\title{
Selecting the Proper Generator for Steam or Gas Turbine Applications
}

\author{
Da Silva Jefferson Joeicemir ${ }^{1,2}$ \\ ${ }^{1}$ BRUSH Electric Machines, Loughborough, England \\ ${ }^{2}$ Department of Energy, University of São Paulo, São Paulo, Brazil
}

Email address:

jefferson.joeicemir@brush.eu

\section{To cite this article:}

Da Silva Jefferson Joeicemir. Selecting the Proper Generator for Steam or Gas Turbine Applications. Journal of Food and Nutrition Sciences. Vol. 5, No. 6, 2017, pp. 225-231. doi: 10.11648/j.jfns.20170506.13

Received: August 16, 2017; Accepted: September 28, 2017; Published: November 16, 2017

\begin{abstract}
The aim of this article is to explore key aspects for a long-lasting and rentable generator. Its motivation comes from the fact that when selecting turbo-generators sets investors and engineers pave much more attention to the turbines details, but generators end up been choice as commodities and as result the whole generation system suffers from availability issues and less return on their investments. This analyse meant to provide insights about key elements to be observed selecting the proper generator, listing aspects that leverage return on investment and reduce total cost of ownership. Technical and commercial equilibrium are assumptions taken as basis for the study and the fundamental question about what are the key elements of a generator specification tried to be answered.
\end{abstract}

Keywords: Turbo-generators, Turbines, Generators, Return on Investments, Technical Specifications, Key Technical Aspects, Availability, Efficiency

\section{Introduction and Motivation}

After several years installing, selecting, repairing, specifying, and selling generators, author has noticed that most of turbo- generators specifications have hundreds of pages dedicated to pressure, temperature and combustible properties, aspects related to the turbine of a turbo generator set, followed by few pages in the end that presents the requirements for the generator. Going back to those installations years later revel several generators present operational problems and efficiency deficits that thermoelectric directors and maintenance people have to leave with, or optionally, it will cost several folds more to revamp the system to what was easier doing during the acquisition stage. This is the motivation behind this article; try to provide insights to investors and engineers about key elements to be observed in the generator side to be less aggressive to the environment, reliable long-lasting generator and, ultimately, enhance return on investment.

\section{Methodology}

This article is structured reviewing some literature articles, and manufacturer's technical and commercial material, however, most of its content is based on over 20 years of experience of the author in the field of electric rotating generators, therefore it does contain certain empiric findings and assumptions. It starts evaluating the procurement chain and respective business metrics where one can deduct that the natural way procurement is made contributes to generators less efficient and with availability issues. After that, key selection aspects are explored, between them temperature, rotor construction aspects, power factor, line and neutral cubicle and efficiency.

\subsection{Procurement Chain \& Respective Business Metrics}

As point to start, one could say that the natural procurement chain and related business metrics collaborate to the way generators could be better selected, two arguments for that are that this is how the market is naturally organized and that generators specification is less depended of end-user interaction. 
In one side as a market organization practice, the OEM with more expensive item become responsible to provide the system, as turbo-generators sets turbines price falls generally between 40 and $80 \%$ of the whole system, most likely the turbine OEM become the direct interface with EPC or the end-user, subcontracting the generator and packing it.

Additionally vapour or gas aspects such as chemical properties, temperatures and pressures are links the process with the turbine; and therefore forces turbine OEMS to interact with end-user calculating back and forward balance of mass under different scenarios and circumstances. This naturally enhance the discussion and quality of the turbine specifications and unfortunately do not happen with the generator, as it is coupled to the turbine shaft and perceived as dependent simply from the torsional torque received from the turbine.

As could be seen, the result is that, the procurement chain naturally creates a bigger interaction between turbine OEM and EPC with end-user and much less discussions happen related to the generators. Figure 1 illustrate a procurement chain with and present respective stakeholders objectives and how the generators get acquired.

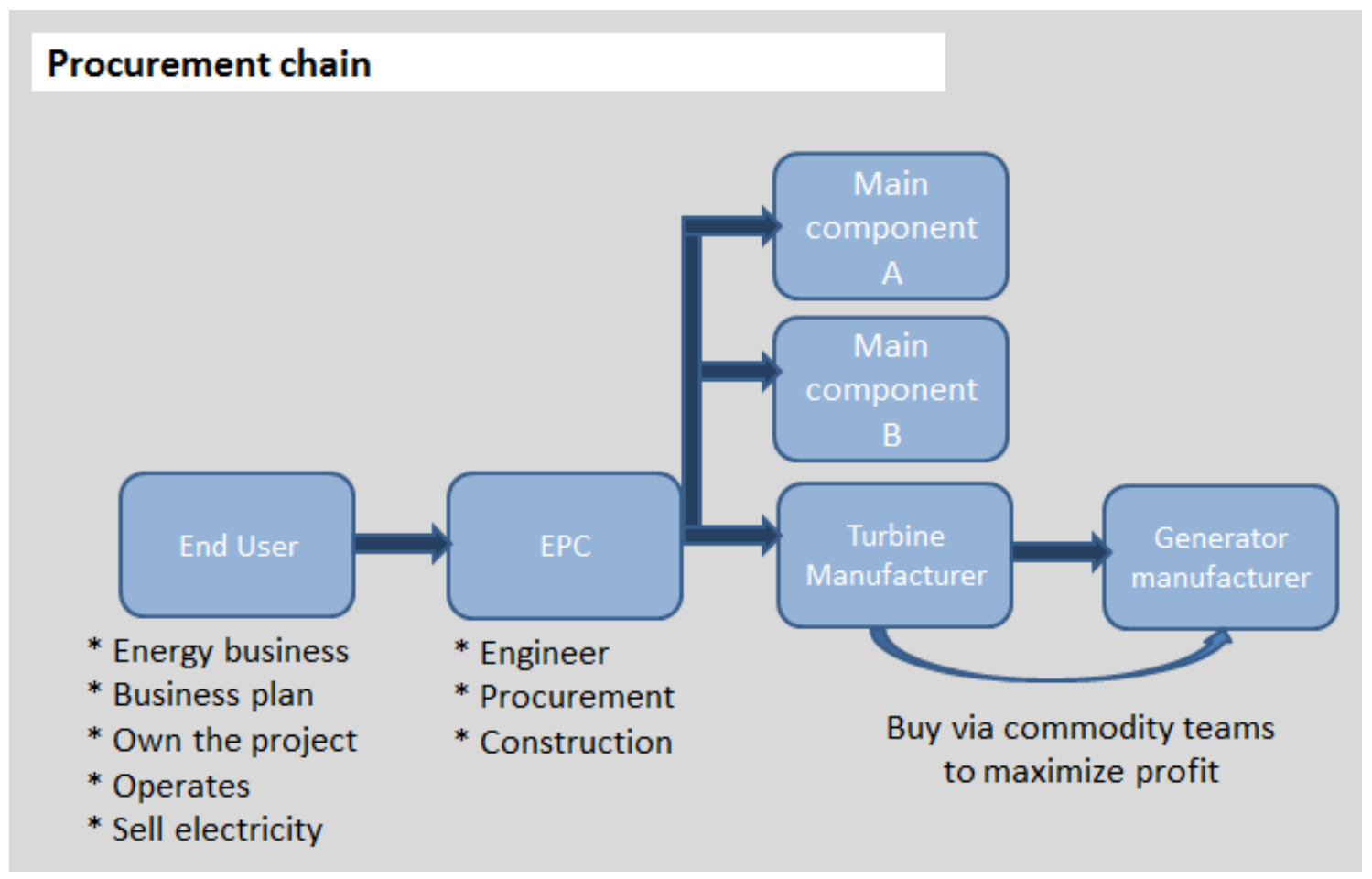

Figure 1. A typical Procurement Chain of Generators.

Different objectives derivate from different metrics, endusers are normally concerned about proper return on investment, low emissions, 20 to 30 years of operational life, high efficiency, support, experience, etc. Whereas turbine manufacturers focus in delivery a high reputable turbine, expending as minimum as possible with generators, prove of it is that several companies today acquire generators via commodities teams.

As could be expected and pointed out by STONE, G. C., et al. [1] Figure 2, manufacturers playing in this market are chased on price to survive and start to design equipment in the limit, every time more $\mathrm{W} / \mathrm{Kg}$ is obtained, not because technology evolves, but because less layer of insulation is used, magnetic circuits and laminations are explored to the limit, thermal losses stressed to the point where it can be, etc. In real terms life span drops dramatically, efficiency become a secondary item and availability issues start to happen.

In summary, the actual scenario described turbine OEMS keeping reputation, reliability and market margins, generators manufacturers that adapt design to the limit to survive and end-users ending-up paying the costs of the natural way procurement chain are organized. Figure 3 try to illustrate it.

\section{$W / \mathrm{kg}$}

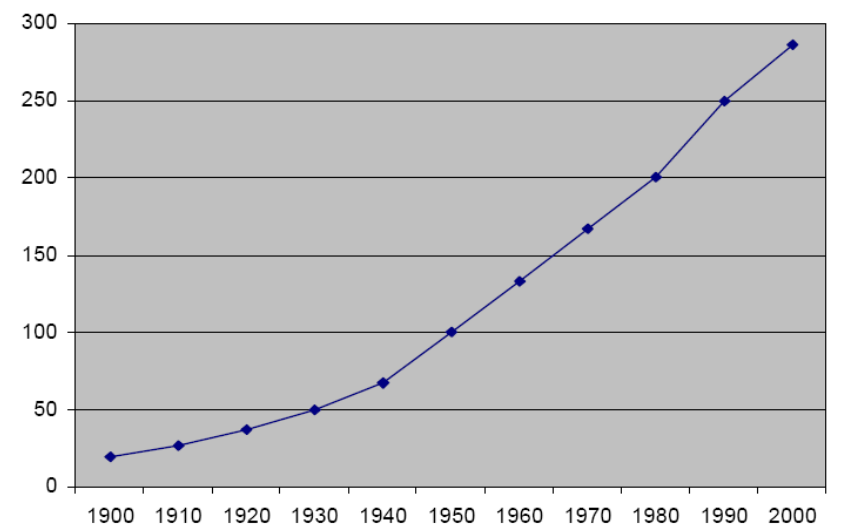

Figure 2. Evolution of W/Kg Generators Ratio. 


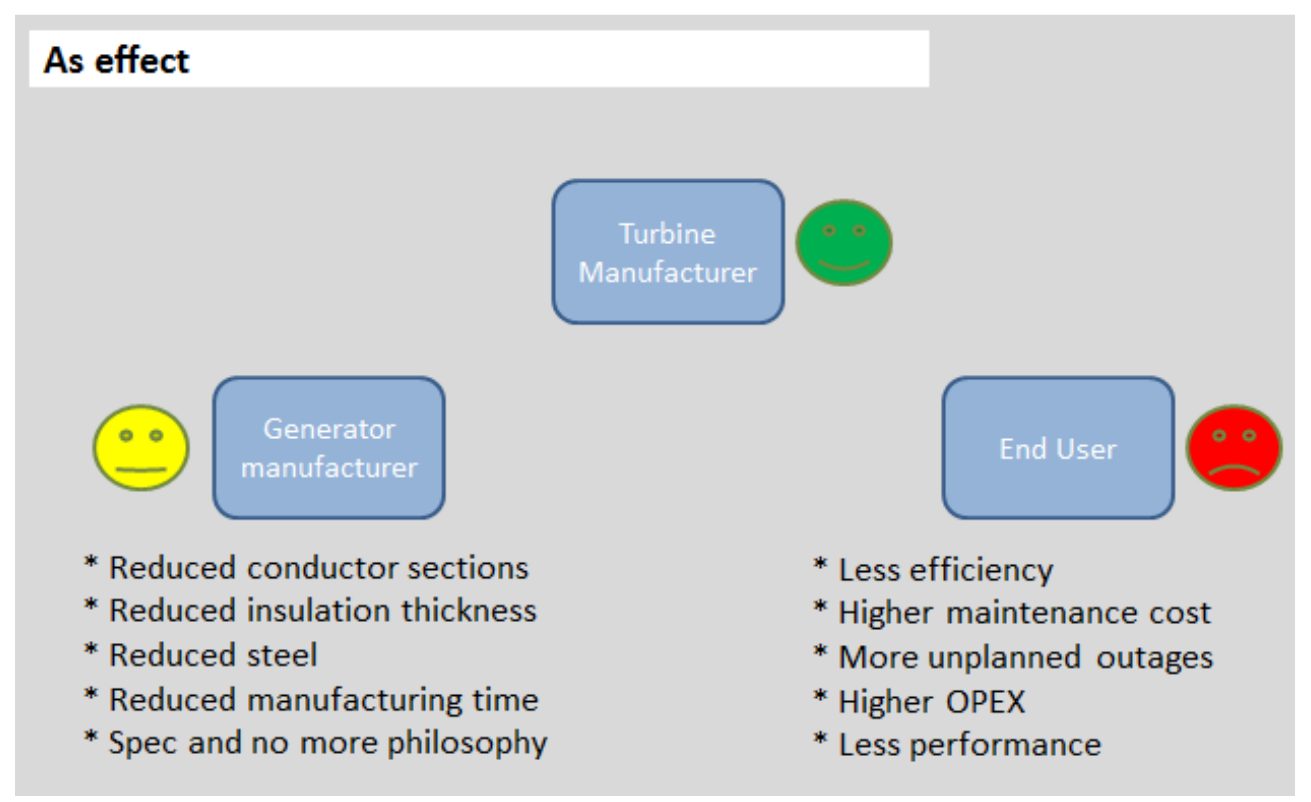

Figure 3. Effects of Actual Procurement Chain and Business Metrics.

As could be seen, procurement chain and business metrics trend to result in generators with efficiency and availability issues, paid by the end-user, who has to protect himself via a specification and quality control methodology, especially during the acquisition time. The intention forward is to work through key element aspects to maximize OPEX and CAPEX.

\subsection{Maximizing OPEX and CAPEX}

Having contextualized the scenario where generators are acquired today, this part explores aspects to maximize return on investment and availability selecting proper generators. A complete specification with years of learned lessons is the answer to obtain this unit that allow optimize in the same time OPEX and CAPEX, however some key elements to be taken in account and it respective fundaments are seen.

\subsection{Temperature of Winding}

Temperature relates to efficiency and availability of a generator, first because reduce thermal losses means increase efficiency, second because as Arrhenius curves indicate an increase in 10 Celsius of a winding system can reduce it dielectric properties lifetime by half [2]. For its importance, it worth to specify generator temperature related aspects properly [5], [6] [9].

One concern is the maximum inlet temperature independent if it is air, water or hydrogen, this need to be properly specified, as figure 4 presents output in MW is hardly depend on it, on this specific air water project, varying from 20 to 30 Celsius may means 5MW of difference. An adequate specification may allow save CAPEX investment without risky exposition.

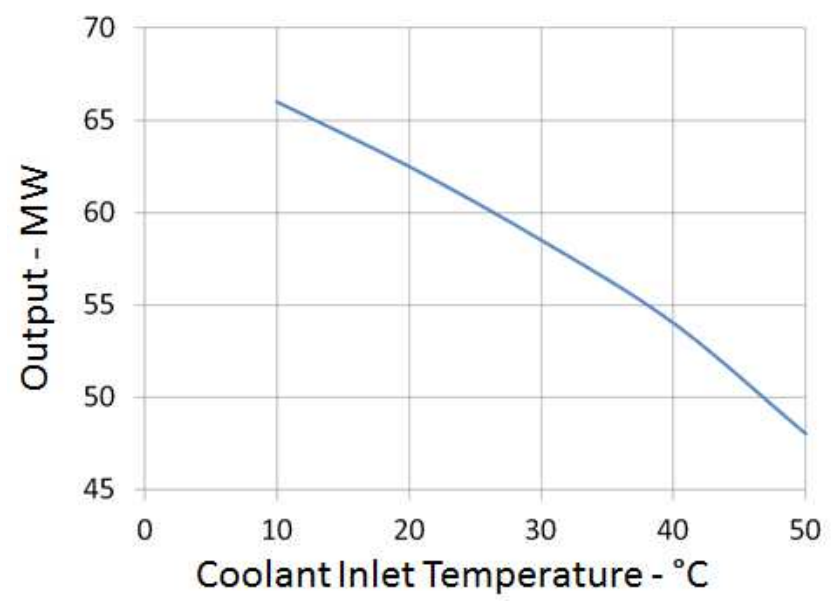

Figure 4. Relationship Between Maximum Inlet Temperature and Rated Output.

Other important aspects in terms of temperature are the insulation class and generator temperature rise.

Concepts are simple but it is highly confused in the market, insulation class relates to the recommended maximum continuous temperature the insulation system is appropriate to be used [3], in other words, how much Celsius they are manufactured to support, divided in standardized levels such as $\mathrm{B}=130$ Celsius, $\mathrm{F}=155$ Celsius and $\mathrm{H}=180$ Celsius.

A second important item, nominated as temperature rise defined by [4], relates to how much temperature is reached under rated load conditions, which means, at 100\% load what is the delta o heating created in the system. Figure 5 presents both insulation class and temperature rise. 


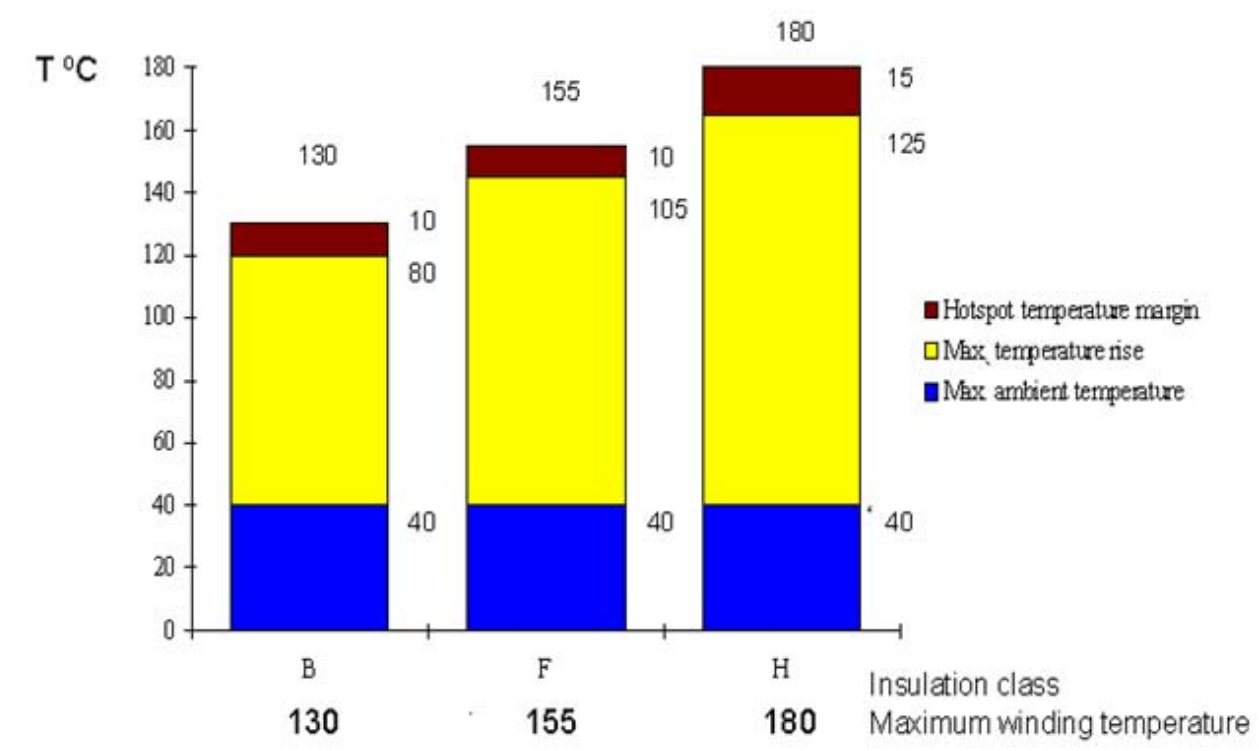

Figure 5. Insulation Class and Temperature Rise.

Figure 5 presents three insulation classes, respectively B, F and $\mathrm{H}$, if $\mathrm{B}$ is taken as example, one can notice that it refers to 130 Celsius, this is the level of temperature that the insulation system is ready to withstand, now as per IEC maximum ambient temperature is considered to be 40 Celsius, and thus when a $\mathrm{B}$ rise happen, the 40 Celsius is increased by 80 degrees reaching 120 , this 80 Celsius therefore reflected the temperature rise.

A common behaviour on different specifications is to determine required insulation class, normally $\mathrm{F}$ for generators above 5MW. However either the temperature rise is left out or customers ask for $\mathrm{F} / \mathrm{F}$ believing that is better than $\mathrm{F} / \mathrm{B}$.

Trying to understand, F class means insulation system ready for 155 Celsius, $\mathrm{B}$ rise with standard ambient temperature means $80+40=120$ Celsius, 120 is the maximum temperature the winding will reach at rated load and continuous power, this means that 155 (maximum supported) 120 (quantity used) $=35$ Celsius are reserve. In essence it does also indicate more material applied to obtain the same output and a bit higher price, however less thermal stress and therefore longer operational life. The decision leads on case by case basis, but it is important that investors and engineers be aware of these aspects when taking decisions.

\subsection{Rotor Construction}

Rotor as known is the rotating part of a generator, if one consider cost; it does mean 30 to $40 \%$ of the generator price. If looked from operational aspect stator is relatively static and because it spins rotors are easier involved in generators failures or downtimes, it can be either due to thermal, electrical, mechanical or ambient variations. Therefore because of costs and related potential downtime, it make sense to invest time and properly specify some rotor aspects.

One of it relates to the rotor body construction, especially when 4 or more poles generators are used. Basically there are two methodologies used, one using forged shaft and salient poles, called simply salient pole, and another either with standard shaft steel or forged material added by magnetic sheets, known as cylindrical rotors.

Salient pole rotors are more stiff and therefore can better withdraw mechanical and thermal disturbances, cylindrical rotors do not requires a higher diameter forged shaft and therefore have a considerable lower cost, however normally vibrates more and works 10 to 15 Celsius hotter, [7] which does means that it demands more maintenance and have a shorter life span [8] [10], as for other aspects, decisions lead on investors and engineers hands, but it does play an important rule and need to be taken in account. Figure 6 present some samples.

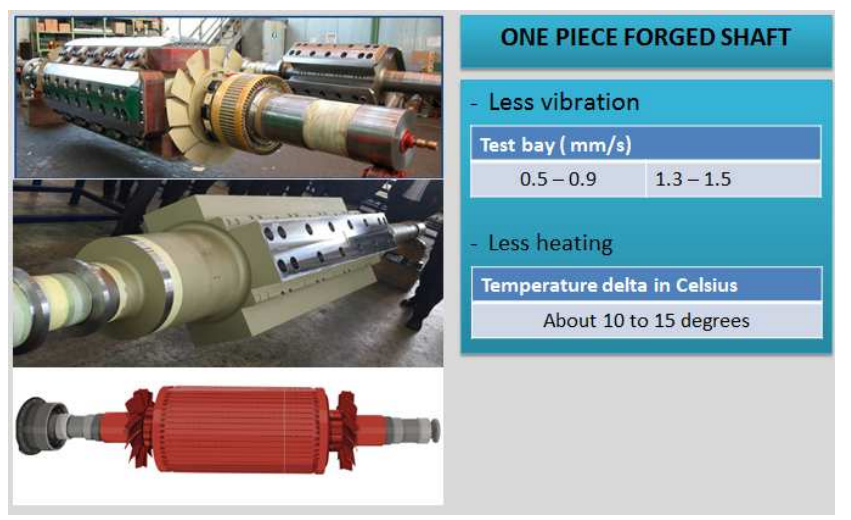

Figure 6. Rotor Construction.

\subsection{Adequate Power Factor}

Power factors relates to the amount on reactive power (VAR), power that is normally not remunerated, a generator unit has to provide to the system. Normally different countries have they own regulations and limits and power plants need to have they consumed quantity as well. A detail analysis requires a power system investigation but this is not the intention of this article, the idea here is only to call attention to not oversize the power factor and then the 
generator unit, as lower the power factor bigger the frame and the generator price, for something that does not get financial compensation. The thumb advice is about 0.2 or 0.5 adds to the grid standard, i.e., if the grid standard requires
0.92, acquire a generator with a power factor of 0.90 may be sufficient. Figure 7 shows how an example about how much an output can vary related to the power factor and maximum inlet coolant temperature.

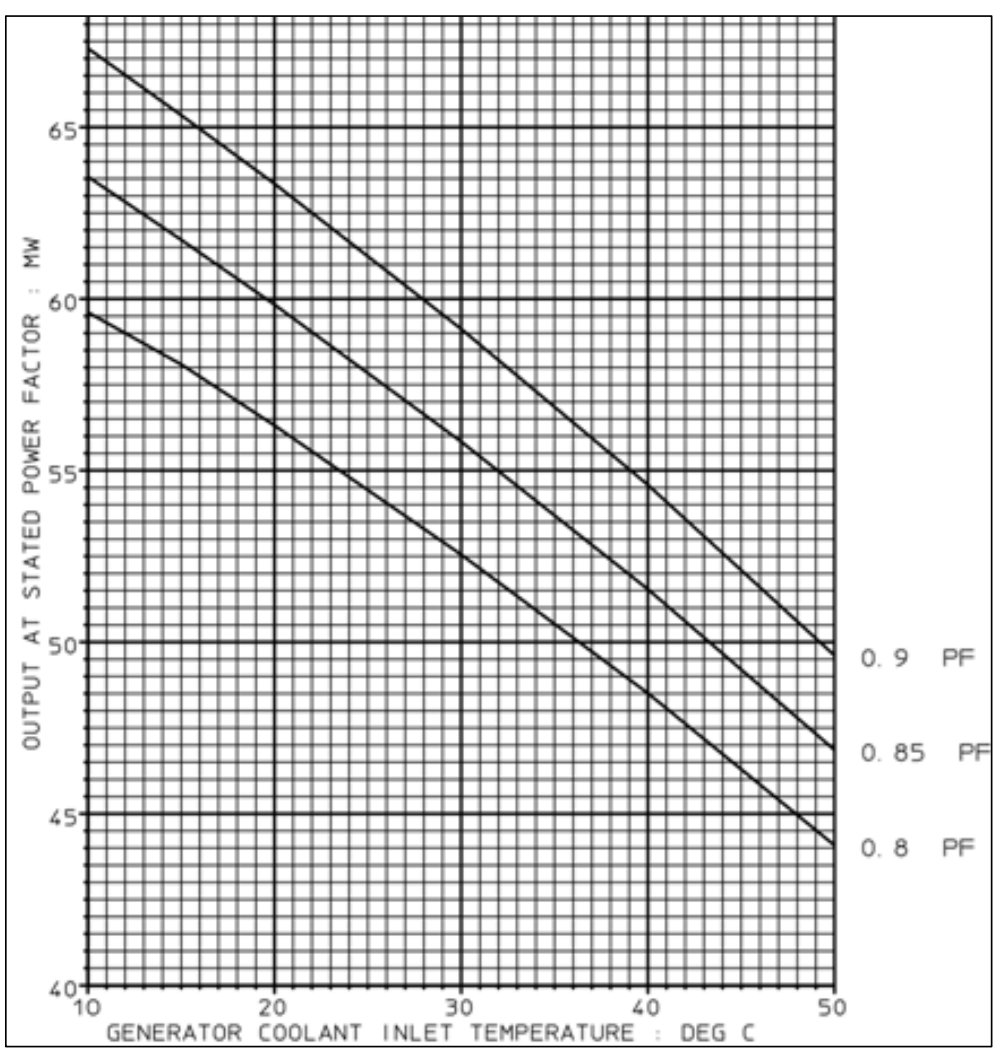

Figure 7. Power Factor Influence on Generator Rated Output.

\subsection{Line and Neutral Cubicle}

Line and neutral cubicles includes auxiliary instrumentation to protect the generator and generate signals for the excitation and control system for the proper operation. It becomes important because has great relationship with installation costs and adequate protection, again CAPEX and OPEX aspects.

Suggestions here are first to specify that line and neutral

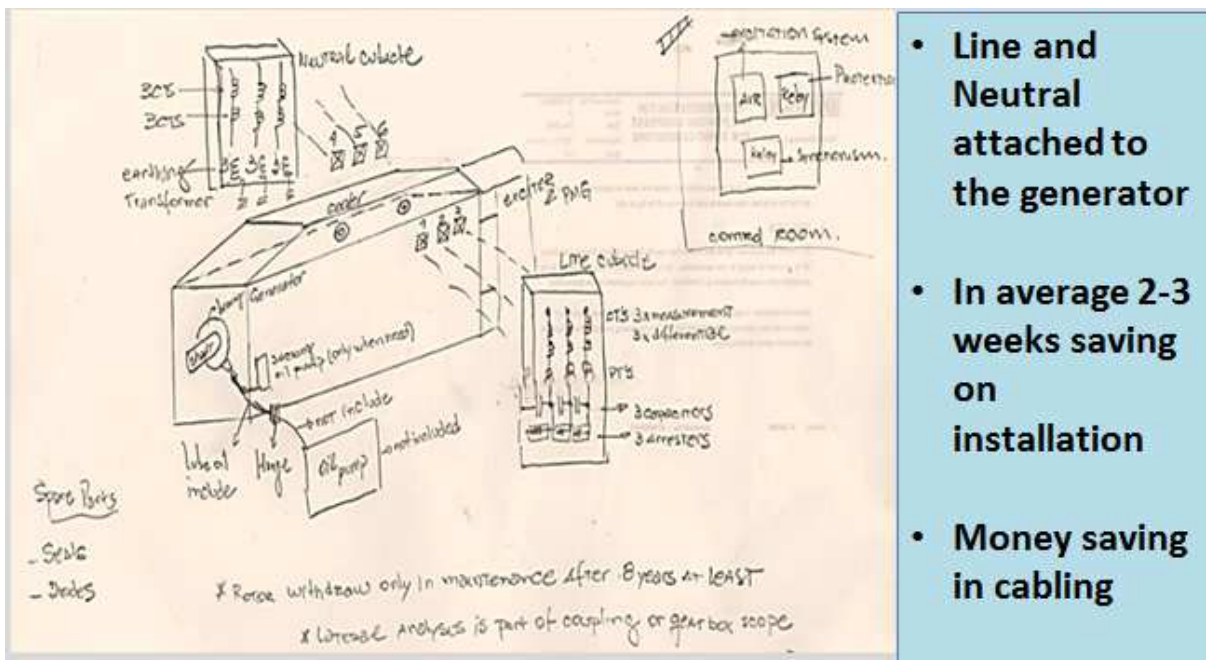

Figure 8. Recommended Location of Line and Neutral Cubicle. cubicle are located aside the generator frame and not in the control room, because this may save between $2-3$ weeks of installation and some kilometres of cabling. (See figure 8). Additionally it important to adequate size the CTs and PTs to excitation, protection, synchronization and control system, especially when those are provided by separate companies or business units within the same company. 


\subsection{Efficiency}

One of the most important aspects that highly influence the technology used and therefore the availability, but even more has relationship with $\mathrm{CO}_{2}$ emissions reduction and higher return on investment is efficiency. On turbine side this may decide the manufacturer or the project viability, the impact on the generator part is smaller, but it can still signify some millions to the project or several tons less of $\mathrm{CO}_{2}$ to the atmosphere.

Argumentations here are based on figure 9 example, where a unit of 20MW with energy priced at $70 \mathrm{USD} / \mathrm{MWh}$ running
8000 hours an year provides 112KUSD increase in revenue per year on each $1 \%$, the amount of power for the same consumption also relates to 2560 ton of $\mathrm{CO}_{2}$ saving. It is an illustrative example and do not consider capability factors, but the generator working almost the full year, however it is brought up to make investors and engineers think about attribute a minimum efficiency level to each generator acquired, let us say at $98 \%$ under $100 \%$ load and power factor 1, additionally to consider if they really want or not use a gear box. All these aspects of generator efficiency in specific should be carefully consider acquiring a new unit.

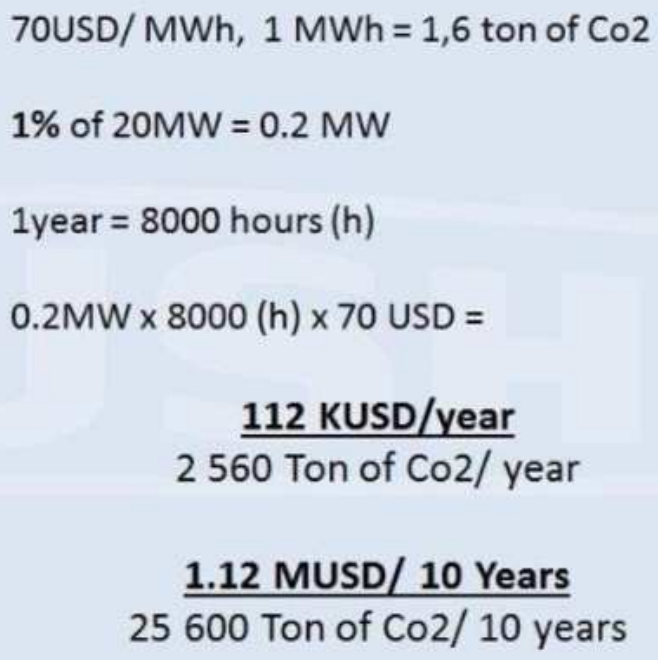

\section{3,36 MUSD/ Generator life time}

Figure 9. Efficiency Influence on Revenue Increase and Emission Reduction.

\section{Conclusions}

This article presented some key elements to be considered when an investor or an engineer is looking for a long lasting and rentable generator. The idea behind is respecting actual market practices of procurement chains and business metrics, allow end-users to maximize they earnings looking after some of the key elements of a generator specification. Temperature, rotor construction, power factor, line and neutral cubicles and efficiency were the main items covered. Figure 10 presents related suggestions for pragmatic person, but always considering that detail requirements are projects specifics. Correct setting of inlet water temperature, insulation class $F$ with elevation $B$, forged shaft constructions, line and neutral cubicle attached to the generator and efficiency of at least $98 \%$ means that end-user take advantages of the value the generator can provide, reaching figures like 30 years or higher operational life time, until $20 \%$ saving in maintenance costs, until 200KUSD saving in installation and shorter paybacks due to better use of combustible or increasing in firm energy sold.

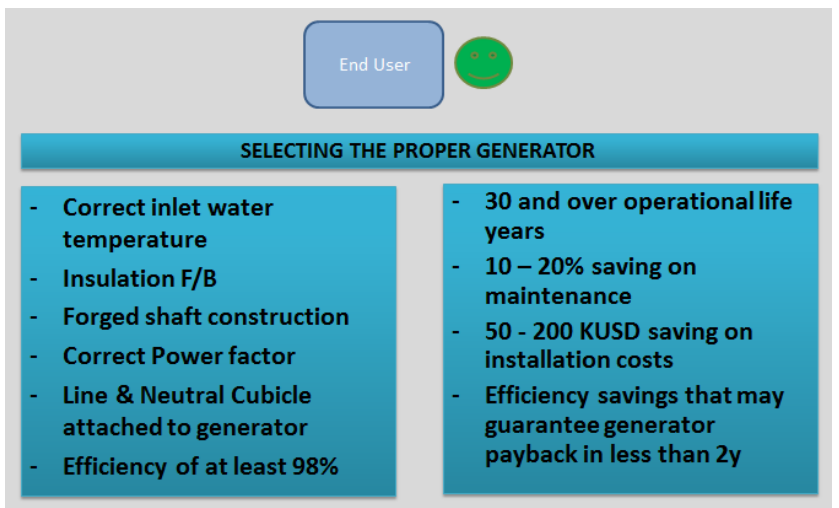

Figure 10. Key Elements and Major Benefits.

\section{References}

[1] Stone, G. C., et al. "Recent problems experienced with motor and generator windings." Petroleum and Chemical Industry Conference, 2009. PCIC 2009. 2009 Record of Conference Papers-Industry Applications Society 56th Annual. IEEE, 2009. 
[2] Klempner, Geoff, and Isidor Kerszenbaum. Handbook of large turbo-generator operation and maintenance. Vol. 38. John Wiley \& Sons, 2011.

[3] Standard, I. E. C. "60085." Electrical Insulation-Thermal Evaluation and Designation.

[4] International Electrotechnical Commission. "IEC 60034-1." International Standard of the International Electrotechnical Commission for Rotating Electrical Machinery 11 (2004).

[5] Timperley, J. E. "Specifying generator testing." Electric Machines and Drives Conference, 2001. IEMDC 2001. IEEE International. IEEE, 2001

[6] Stephan, C-E., and Z. Baba. "Specifying a turbogenerator's electrical parameters guided by standards and grid codes." Electric Machines and Drives Conference, 2001. IEMDC 2001. IEEE International. IEEE, 2001.

[7] Boldea, Ion. Synchronous generators. CRC Press, 2015.

[8] Spisak, A. J. "Guideline for specifying air cooled combustion turbine generators." Electric Machines and Drives, 1999. International Conference IEMD'99. IEEE, 1999.
[9] Fogarty, J. M. "Connections between generator specifications and fundamental design principles." Electric Machines and Drives Conference, 2001. IEMDC 2001. IEEE International. IEEE, 2001.

[10] Kar, Narayan C., Toshiaki Murata, and Junji Tamura. "Characteristic of cylindrical-rotor synchronous generator." IEEE Transactions on Energy Conversion 15.3 (2000): 269276.

\section{Biography}

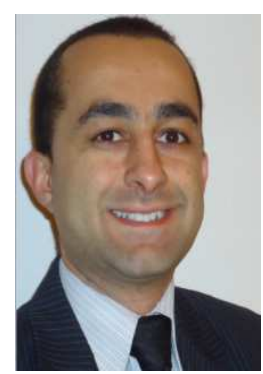

Da Silva Jefferson Joeicemir is an electrical engineer with 20 years' experience in the field of electrical rotating machines. He has a Master's in International Business, MBA in strategic management and specialization in Energy. Jefferson work for BRUSH Electrical Machines.

https://www.linkedin.com/in/jeffersonjoeicemir-da-silva-76526215/ 